\title{
Physical and Functional Properties of Some Millet Varieties of Assam
}

\author{
Sushmita Khatoniar* and Pranati Das \\ Department of Food Science and Nutrition, College of Community Science, \\ Assam Agricultural University, Jorhat, Assam-785013, India \\ *Corresponding author
}

\section{A B S T R A C T}

Ke y w o r d s
Millets, Physical
properties,
functional
properties

Physical properties are necessary for the design of equipment to handle, transport, process and store the crop. Physical properties such as length, breadth, thickness, thousand grain weight, thousand grain volume etc. were studied for three millet varieties such as finger millet, foxtail millet and proso millet which are grown in Assam. In the present study, the length, breadth and thickness of proso millet was highest among the other two millets. Bulk density of finger millet, foxtail millet and proso millet were $0.71 \mathrm{~g} / \mathrm{ml}, 0.73 \mathrm{~g} / \mathrm{ml}$ and $0.79 \mathrm{~g} / \mathrm{ml}$ respectively. The water and oil absorption capacity were highest in foxtail millet flour $(1.26 \mathrm{ml} / \mathrm{g}$ and 1.18 $\mathrm{ml} / \mathrm{g}$ respectively) and lowest in proso millet flour $(1.14 \mathrm{ml} / \mathrm{g}$ and $1.16 \mathrm{ml} / \mathrm{g}$ respectively). The physical and functional properties are important for engineers, designers, scientists and processors in designing equipment for millet grain processing. Results are likely to be useful in assessing the quality of grains used while preparing the flour.

\section{Introduction}

Millets are small seeded grasses that grow on dry zones as rain fed crops, under marginal conditions of soil fertility and moisture. Millets are one of the oldest foods known to humans and probably the first cereal grain to be used for domestic purposes (Sharma, 2008). The millets can be classified broadly into two types for convenience namely, major and minor millets based on their seed size. Major millets includes sorghum (Sorghum vulgare), finger millet (Eleusine coracana) and pearl millet (Pennisetum glaucum), while minor millets include little (Panicum miliare), proso (Panicum miliaceum), kodo (Paspalum scrobiculatum), Italianor foxtail (Setaria italica) and barnyard millet (Echinochloa frumantacea).

Small millets are small grained cereals and are the staple food of the millions inhabiting the arid and semiarid tropics of the world. Millets are distributed in most of the Asian 
and African countries and parts of Europe. They are the most important species in terms of cropped area and contributions to food security in regions of Africa and Asia (Rao, et al., 2011).

Millet grains account for about one sixth of the total food grain production hold an important place in the food grain economy of India. The millet production is dominated by South and East Asia (about 60\%), Eurasia and Central Asia (14\%), Africa (16\%) and rest of the World (10\%). India is the largest producer of millet grains, producing about $33-37 \%$ of a total of 28 million tonnes of the world produce. Finger millet represented about 81 per cent of the minor millets produced in India and the rest by kodo millet, foxtail millet and little millet (Pradhan et al., 2010). The world total production of millet grains at last count was 762712 metric tons and the top producer was India with an annual production of 334500 tons $(43.85 \%)$ (FAO, 2012).

Millets are highly nutritious, non-glutinous and non-acid forming foods. Hence, they are soothing and easy to digest. They are considered to be the least allergenic and easily digestible grains available. Millets contain about 8 per cent protein and 4 per cent fat. Millets are rich source of vitamins and minerals. Millets are especially rich in calcium. The dietary carbohydrate content of millets is also relatively high. Starch is the main carbohydrate component and they contain a higher proportion of nonstarchypolysaccharides (dietary fiber) also. Prolamines and glutelins form the major portion of their proteins. The fats from millets contain a higher portion of unsaturated fatty acids and supply essential fatty acids. Although a considerable portion of nutrients is concentrated in the seed coat, the bioavailability of the nutrients present in the endosperm is higher than the seed coat nutrients.
Anti-nutritional factors such as phytate and polyphenols are also present in millets but they are mostly confined to the seed coat and the milled millets are generally free from the anti-nutritional factors (Kumaret al., 2010).

A few varieties of millets such as finger millet, foxtail millet and proso millet are sporadically grown and consumed in some parts of Assam especially in lower Assam and adjoining North-Eastern states. Therefore, to make people aware about the quality parameters of these millets as compared to other cereal grains, the present study was designed with the following objective, viz., to determine the physical and functional properties of these millet grains and flours.

\section{Materials and Methods}

\section{Collection of sample}

Finger millet, foxtail millet and proso millet was procured from the farmer's field of Gosaigaon, Kokrajhar district of Assam.

\section{Processing of sample}

Sample was cleaned thoroughly to remove all foreign matters, broken and immature grains. The grains were dehusked and then ground to a fine flour to pass through B.S. 60 mesh sieve employing an electrical grinder. The grinding operation was conducted below $40^{\circ} \mathrm{C}$. The flours obtained were stored at $4^{\circ} \mathrm{C}$ in air tight containers and used for analysis.

\section{Determination of physical properties of grain}

Physical properties of the millets were evaluated in terms of length, breadth, thickness, /breadth ratio, geometric mean diameter, arithmetic mean diameter, thousand grain weight, thousand grain volume, bulk density etc. 


\section{Length, breadth and thickness}

The length, breadth and thickness of 10 randomly selected grains from 10 different lots were measured and the average measurements were expressed in $\mathrm{mm}$.

\section{Length/breadth ratio}

The length/breadth ratio was obtained by dividing length $(\mathrm{mm})$ by its corresponding breadth $(\mathrm{mm})$.

\section{Geometric mean diameter (GMD)}

GMD was carried out as described as (Mohsenin, 1970). The spatial dimensions namely length (longest dimension, L), breadth (second longest dimension, B) and thickness (third longest dimension, $\mathrm{T}$ ) were measured for ten representative grains and the geometric mean diameter (GMD) was calculated as equivalent diameter.

$\mathrm{GMD}=(\mathrm{L} \times \mathrm{B} \times \mathrm{T})^{1 / 3}$

\section{Arithmetic mean diameter (AMD)}

AMD was carried out as described as (Mohsenin, 1970). The spatial dimensions namely length (longest dimension, L), breadth (second longest dimension, B) and thickness (third longest dimension, T) were measured for ten representative grains and the arithmetic mean diameter (AMD) was calculated as equivalent diameter.

$\mathrm{AMD}=(\mathrm{L} \times \mathrm{B} \times \mathrm{T}) / 3$

\section{Sphericity}

According to Mohsenin (1970), the degree of sphericity, $\varphi$ can be expressed as follows:

$$
\varphi=\frac{(\text { LWT })^{1 / 3}}{\mathrm{~L}}
$$

where $\mathrm{L}$ is the grain length, $\mathrm{W}$ the grain width and $\mathrm{T}$ is the grain thickness.

\section{Thousand grain weight}

One hundred grains of samples were counted randomly from the five different lots and their weight in grams was determined by weighing in a sensitive electronic balance. Each weight was multiplied by 10 to obtain the thousandgrain weight.

\section{Thousand grain volume}

One hundred grains of samples were taken randomly from the five different lots and their volume in a graduated cylinder was recorded. Each volume was multiplied by 10 to obtain thousand-grain volume. The thousand-grain volume was expressed in $\mathrm{ml}$.

\section{Bulk density}

The bulk density was calculated from the bulk volume of $100 \mathrm{~g}$ of samples in a $250 \mathrm{ml}$ graduated cylinder. The grains were gently poured into the cylinder and the cylinder was then tapped on the table for uniform packing. Average of 5 replications was taken. The bulk density was expressed in g/ml(Carman, 1996 and Konak et al., 2002).

$$
\begin{gathered}
\text { Bulk density }(\mathrm{g} / \mathrm{ml})=\text { Weight of the sample in air }(\mathrm{gm}) \\
\text { Volume of sample }(\mathrm{ml})
\end{gathered}
$$

\section{True density}

True density ( $\rho t)$ was determined using the toluene displacement method (Mohsenin 1986). Toluene $(0.2 \mathrm{~L})$ was filled in a $0.5 \mathrm{~L}$ graduated measuring cylinder and $0.1 \mathrm{~kg}$ seeds were immersed in it. The amount of toluene displaced was recorded. The true density was estimated as the ratio of sample mass to the volume of displaced toluene. 


\section{Porosity}

The porosity was calculated by using the formula:

$$
\operatorname{Porosity}(\%)=1-\frac{\text { Bulkdensity }}{\text { Truedensity }}
$$

\section{Determination of functional properties of millet flours}

\section{Water absorption capacity (WAC)}

The water absorption capacity of the millet flours was determined by the method of (Elhardallou and Walker, 1993). $15 \mathrm{ml}$ of distilled water was added $100 \mathrm{~g}$ of the flour in a weighed $25 \mathrm{ml}$ centrifuge tube. The tube was agitated on a vortex mixer for $2 \mathrm{~min}$. It was centrifuged at $4000 \mathrm{rpm}$ for 20 minutes. The clear supernatant was decanted and discarded. The adhering drops of water was removed and the reweighed. Water absorption capacity is expressed as the weight of water bound by $100 \mathrm{~g}$ of dried flour.

\section{Oil absorption capacity (OAC)}

Oil absorption capacity (OAC) of the millet flour was determined using the method of (Sathe and Salunkhe, 1981). $10 \mathrm{ml}$ of refined com oil was added $100 \mathrm{~g}$ of the flour in a weighed 25 centrifuge tube. The tube was agitated on a vortex mixer for $2 \mathrm{~min}$. It was centrifuged at $4000 \mathrm{rpm}$ for $20 \mathrm{~min}$. The volume of free oil was recorded and decanted. Oil absorption capacity is expressed as $\mathrm{ml}$ of oil bound by $100 \mathrm{~g}$ of dried flour.

\section{Foaming capacity and foaming stability}

The foaming capacity (FC) and the foam stability (FS) of the flour samples were determined by slightly modifying the procedure followed by Kaur and Singh (2005).
The dispersion of flour samples in $50 \mathrm{ml}$ of distilled water at the rate of $3 \%$ w/v was homogenized vigorously for 3 to $5 \mathrm{~min}$ using a high-speed scattering machine at 10,000 $\mathrm{rpm}$. The blend is immediately transferred to a graduated cylinder and the homogenizer cup was rinsed with $10 \mathrm{~mL}$ distilled water, which was then added to the graduated cylinder. The volume was recorded before and after whipping and measured as the percent of volume increase due to whipping. The foaming capacity was expressed as the percentage of volume increase.

For the determination of foaming stability, a change in the foam volume in the graduated cylinder was recorded after $1 \mathrm{~h}$ of storage.

The FC and FS were calculated by the following formulas.

$$
\begin{aligned}
& F C(\%)=\frac{V_{2}-V_{1}}{V_{2}} \times 100 \\
& F S(\%)=\frac{V_{3}}{V_{2}-V_{1}} \times 100
\end{aligned}
$$

\section{Swelling power}

Swelling power was estimated as per Schoch (1964). Five hundred milligram (W1) of the sample was weighed, placed into centrifuge tube and the centrifuge tube with sample was weighed (W2). Twenty $\mathrm{ml}$ of distilled water was added (VE) and heated for $30 \mathrm{~min}$ in a water bath at $90^{\circ} \mathrm{C}$, with occasional stirring, the tubes were cooled and centrifuged at $5000 \mathrm{rpm}$ for $10 \mathrm{~min}$. The supernatant was decanted into a pre-weighed (W4) petriplate and dried at $105^{\circ} \mathrm{C}$ and weighed (W5). The inner side of the centrifuge tube was wiped, dried and weighed (W3). Per cent swelling power was calculated using the following formulae: 


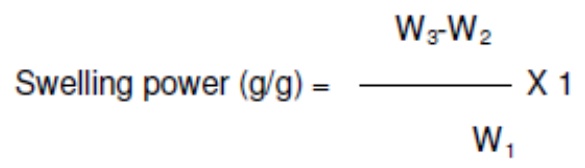

\section{Results and Discussion}

\section{Physical properties of millet grains}

The physical properties of millet grains are presented in the Table 1. In the present study, minimum length was observed in case of foxtail millet grains $(1.87 \mathrm{~mm})$ followed by finger millet $(1.92 \mathrm{~mm})$ and proso millet $(2.36$ $\mathrm{mm})$. In the same manner, breadth and thickness was highest in proso millet (1.85 $\mathrm{mm}$ and $1.41 \mathrm{~mm}$ respectively) and lowest in foxtail millet $(1.68 \mathrm{~mm}$ and $1.35 \mathrm{~mm}$ respectively).

Similar observation was reported in other studies where the length, breadth and thickness of foxtail millet (Setaria itatica): variety-HMT 1001 were $2.17 \mathrm{~mm}, 1.59 \mathrm{~mm}$ and $1.45 \mathrm{~mm}$ respectively (Sunil et al., 2016). The length, breadth, thickness and length/breadth ratio of whole grainkodo millet were found $2.61 \mathrm{~mm}, 1.96 \mathrm{~mm}, 1.33 \mathrm{~mm}$ and $1.33 \mathrm{~mm}$ respectively (Kumar et al., 2016). The geometric mean diameter and arithmetic mean diameter was also highest in proso millet in the present study.

Thousand grain weight of finger millet, proso millet and foxtail millet were $3.12 \mathrm{~g}, 4.85 \mathrm{~g}$ and $2.10 \mathrm{~g}$ respectively. Similarly, thousand grain volume were in the range of $3.21 \mathrm{ml}$ (foxtail millet) to $5.07 \mathrm{ml}$ (proso millet).

Vidhyavathi (2001) analyzed the physical characteristics of brown and white varieties of finger millet and found that in brown varieties thousand grain weight ranged from 2.2 to $3.1 \mathrm{~g}$, thousand seed volume ranged from 2.0 to $2.5 \mathrm{ml}$. In a similar study, Thilagavathi et al., (2015) reported that maximum thousand grain weight was observed in pearl millet
(11.39 g) followed by kodo millet (2.45 g)and little millet $(2.23 \mathrm{~g})$. The differences in the parameters of the present study might be due to differences in environmental conditions during plant development, the position in the panicle (the better developed grains are on the top of the panicle) and also the varietal differences.

Bulk density is a function of the closeness of packaging. The values for bulk density of the samples ranged from 0.71 to $0.79 \mathrm{~g} / \mathrm{ml}$ respectively. Bulk density of finger millet, foxtail millet and prosomillet were $0.71 \mathrm{~g} / \mathrm{ml}$, $0.73 \mathrm{~g} / \mathrm{ml}$ and $0.79 \mathrm{~g} / \mathrm{ml}$ respectively. The difference of bulk densities may be due to the fact that it is influenced by many factors.

Gaines et al., (1998) reported that rain causes grain kernels to swell but subsequent drying does not return some layers of the pericarp to their original pre-rain size, leaving some of the pericarp layers to exhibit a loose or puffed appearance. These changes cause decrease of grain density and test weight, but do not influence the flour yield.

The true densities of the raw materials used were in the range of $1.12-1.28 \mathrm{~g} / \mathrm{ml}$ where finger millet being the lowest and proso millet being the highest value. Various factors like moisture content, pest infestation, maturity etc. affects the density of grains.

Various functional properties of the flour of raw materials used such as water absorption capacity, oil absorption capacity, foaming capacity, swelling power etc. were evaluated to assess flour quality. The water and oil absorption capacity were highest in foxtail millet flour $(1.26 \mathrm{ml} / \mathrm{g}$ and $1.18 \mathrm{ml} / \mathrm{g}$ respectively) and lowest in proso millet flour $(1.14 \mathrm{ml} / \mathrm{g}$ and $1.16 \mathrm{ml} / \mathrm{g}$ respectively). Foaming capacity was highest in finger millet flour $(21.55 \%)$ and foam stability was highest in foxtail millet flour (4.97 \%). 
Table.1 Physical dimensions of the raw materials

\begin{tabular}{|l|c|c|c|}
\hline Parameters & Finger millet & Foxtail millet & Proso millet \\
\hline Length $(\mathbf{m m})$ & $1.92 \pm 0.11$ & $1.87 \pm 0.06$ & $2.36 \pm 0.12$ \\
\hline Breadth $(\mathbf{m m})$ & $1.73 \pm 0.02$ & $1.68 \pm 0.02$ & $1.85 \pm 0.03$ \\
\hline Length/ Breadth ratio & $1.11 \pm 0.03$ & $1.11 \pm 0.10$ & $1.27 \pm 0.03$ \\
\hline Thickness (mm) & $1.26 \pm 0.04$ & $1.35 \pm 0.01$ & $1.41 \pm 0.01$ \\
\hline Geometric Mean Diameter (mm) & $1.75 \pm 0.20$ & $1.66 \pm 0.18$ & $1.80 \pm 0.13$ \\
\hline Arithmetic Mean Diameter (mm) & $1.76 \pm 0.02$ & $1.67 \pm 0.04$ & $1.83 \pm 0.03$ \\
\hline Sphericity & $0.91 \pm 0.01$ & $0.89 \pm 0.04$ & $0.83 \pm 0.02$ \\
\hline
\end{tabular}

Mean \pm Standard deviation

Table.2 Weight, volume and densities of the raw materials

\begin{tabular}{|l|c|c|c|}
\hline Parameters & Finger millet & Foxtail millet & Proso millet \\
\hline Thousand grain weight $\mathbf{( g )}$ & $3.12 \pm 0.06$ & $2.10 \pm 0.14$ & $4.85 \pm 0.22$ \\
\hline Thousand grain volume $(\mathbf{m l})$ & $4.34 \pm 0.08$ & $3.21 \pm 0.02$ & $5.07 \pm 0.02$ \\
\hline Bulk density & $0.71 \pm 0.02$ & $0.73 \pm 0.03$ & $0.79 \pm 0.03$ \\
\hline True density & $1.12 \pm 0.08$ & $1.25 \pm 0.06$ & $1.28 \pm 0.14$ \\
\hline Porosity & $0.37 \pm 0.03$ & $0.42 \pm 0.02$ & $0.38 \pm 0.04$ \\
\hline
\end{tabular}

Mean \pm Standard deviation

Table.3 Functional properties of the raw materials

\begin{tabular}{|l|c|c|c|}
\hline Parameters & Finger millet flour & $\begin{array}{c}\text { Foxtail millet } \\
\text { flour }\end{array}$ & Proso millet flour \\
\hline Water absorption capacity (ml/g) & $1.21 \pm 0.04$ & $1.26 \pm 0.05$ & $1.14 \pm 0.02$ \\
\hline Oil absorption capacity (ml/g) & $1.11 \pm 0.11$ & $1.18 \pm 0.06$ & $1.16 \pm 0.17$ \\
\hline Foaming capacity (\%) & $21.55 \pm 0.02$ & $20.57 \pm 0.02$ & $21.22 \pm 0.10$ \\
\hline Foam stability (\%) & $4.65 \pm 0.03$ & $4.97 \pm 0.03$ & $4.77 \pm 0.03$ \\
\hline Swelling power (\%) & $4.33 \pm 0.01$ & $4.78 \pm 0.05$ & $4.56 \pm 0.19$ \\
\hline
\end{tabular}

Mean \pm Standard deviation

According to Ghavidel and Prakash (2006) carbohydrate composition may also be a factor influencing the water holding capacity of the flours. It is known that polysaccharides, which are hydrophilic in nature greatly, affect water absorption capacity. Due to the removal of the husk the hydrophilic polysaccharides may be lost resulting in the decrease of water absorption capacity by polished grain flours. The oil absorption capacity of any food material relies mainly on its capacity to physically entrap oil by a complex capillary attraction process. Fat acts as a flavor retainer, a consistent trait and an enhancer of mouth feel (Khattab and Amtfield, 2009).

The food industries are focusing on less exploited ingredients as the challenges of processing health promoting food product increases. In the present study, as light 
variation in the physical and functional properties was found among the millets. Therefore, data obtained on the physical and functional properties of millets may measure the quality of grains used to produce flours for further use.

\section{References}

Carman, K. (1996). Some physical properties of lentil seeds. J. Agric. Eng. Res. 63(2):87-92

Elhardallou, S.B. and Walker, A. F.(1993). The water holding capacity of three starchy legumes in the raw, cooked and fibre-rich fraction forms. Plant Foods Hum. Nutr. 44: 171-179.

FAO (2012). Food and Agricultural Organization. Economic and Social Department: The Statistics Division 2012. Available from FAO

[http://faostat.fao.org/site/567/DesktopDefa ult.aspx? Page ID = 567] Posted on September 29, 2012.

Gaines C.S., Finney P.L., Fleegoe M.L., Andrews L.C. (1998) Use of aspiration and the Single Kernel Characterization System to evaluation the puffed and shriveled condition of soft wheat grain. Cereal Chem., 75(2), 207-211.

Ghavidel, R.A. and Prakash, J. (2006) Effect of germination and dehulling on functional properties of legume flours. J. Sci. Food Agril. 86: 1189-1195.

Kamara, M.T., Zhou, H.M., Zhu, K.X., Amadou, I. and Tarawalie, F.(2009).Comparative study of chemical composition and physicochemical properties of two varieties of defatted foxtail millet flour grown in China. Am. J. Food Technol. 4(3): 255-267.

Kaue, M. and Singh, N. (2006). Relationships between selected properties of seeds, flours and starches from different chickpea cultivars. Int. J. Food Prop. 9:597-608.

Khattab, R.Y. and Arntfield, S.D. (2009). Functional properties of raw and processed canola meal. Food Sci. Technol. 42:1119-
1124.

Konak, M., Çarman, K. and Aydin, C.(2002). Physical properties of chick pea seeds. Biosys. Eng. 82(1): 73-78.

Kumar, K., Rekha and Sinha, L.K. (2010). Evaluation of quality characteristics of soybased millet biscuits. Advances in Applied Science Research. Pelagia Reseach Library. 1(3): 187-196.

Mohasenin, N. N. (1970). Physical properties of plant and materials. New York: Gordon and Breach Science Publishers.

Mohsenin, N.N. (1986). Physical properties of plant and animal materials. Gordon and Breach Science Publishers, New York.

Pradhan, A., Nag, SK and Patil, SK. (2010), Dietary management of finger millet (Eleusine coracana L. Gaerth) controls diabetes. Curr Sci., 98(6):763-5.

Rao, B.R.; Kumar, M.H.; Nagasampige, $\mathrm{H}$ and Ravikiran, M. (2011). Evaluation of nutraceutical properties of selected small millets. J. Pharm. Bioall. Sci. 3(2):277-279.

Schoch, T.J. (1964), Swelling power and solubility of granular starches. In carbohydratechemistry. Ed. Wristler, R.L, Smith, R.J., Bemiller, N.J. and Wolform, M.I.,Academic Press, New York, pp. 106 108.

Sharma, P., (2008) Minor millets of tribal area, Agrotech Publishing Academy, Udaipur, India.

Sunil, C.K.; Venkatachalapathy, N.; Shanmugasundaram, S.; Pare, A. and Loganathan, M. (2016). Enginneering properties of foxtail millet (Setariaitalica L): variety- HMT 1001. Intern. J.Sci. Environ. Technol. 5(2):632-637.

Thilagavathi, T., Banumathi, P., Kanchana, S. and Ilamaran, M., Effect of heat moisture treatment on functional and phytochemical properties of native and modified millet flours. Plant Arch. 15(1): 15-21 (2015).

Vidyavathi, H.G. (2001), M.Sc. Thesis, UAS, GKVK, Bangalore, 42-45. 


\section{How to cite this article:}

Sushmita Khatoniar and Pranati Das. 2020. Physical and Functional Properties of Some Millet Varieties of Assam. Int.J.Curr.Microbiol.App.Sci. 9(05): 1508-1515. doi: https://doi.org/10.20546/ijcmas.2020.905.171 